\title{
Electrochemical Properties of Boron-Doped Diamond Electrodes Prepared by Hot Cathode Direct Current Plasma CVD
}

\author{
Hong Yan PENG ${ }^{1}$ *, Wan Bang ZHAO $^{2}$, Hong Wei JIANG ${ }^{3}$, Lin Mao WANG ${ }^{1}$, \\ Meng Mei PAN ${ }^{1}$
}

\author{
${ }^{1}$ Physics and Electronic Engineering College of Hainan Normal University, Haikou, 571158, PR China \\ ${ }^{2}$ School of Automotive Engineering, Dalian University of Technology, Dalian,116024, PR China \\ ${ }^{3}$ Mudanjiang Normal College, Mudanjiang 157012, PR China \\ cross $^{\text {ref }}$ http://dx.doi.org/10.5755/j01.ms.22.2.12926
}

Received 20 August 2015; accepted 19 February 2016

\begin{abstract}
A series of boron-doped diamond (BDD) films were deposited by using a hot cathode direct current plasma chemical vapor deposition(HCDC-PCVD) system with different ratios of $\mathrm{CH}_{4} / \mathrm{H}_{2} / \mathrm{B}\left(\mathrm{OCH}_{3}\right)_{3}$ (trimethylborate) gas mixture. The morphology, structure and quality of BDD films were controled by SEM, XRD and Raman measurements. The electrochemical properties of the BDD films were investigated by electrochemical methods. Cyclic voltammetric performances of the BDD films indicated that the main determinant in the electrochemical characteristics of BDD films was the boron doping amount. The threshold potential for oxygen evolution increased from $1 \mathrm{~V}$ to $2.5 \mathrm{~V}$. Meanwhile, the electrochemical potential window of BDD films was enlarged from $2.2 \mathrm{~V}$ to $4.5 \mathrm{~V}$ when the $\mathrm{B}$ content was increased from $1.75 \times 10^{19} \mathrm{~cm}^{-3}$ to $2.4 \times 10^{21} \mathrm{~cm}^{-3}$. The cyclic voltammograms of BDD films in $\mathrm{K}_{4} \mathrm{Fe}(\mathrm{CN})_{6}$ and $\mathrm{K}_{3} \mathrm{Fe}(\mathrm{CN})_{6}$ mixed solution indicated that the behavior of $\mathrm{Fe}(\mathrm{CN}) 6^{-3 /-4}$ redox couple could be regarded as semi-reversible.

Keywords: hot cathode direct current plasma CVD, boron-doped diamond films, electrochemical properties.
\end{abstract}

\section{INTRODUCTION}

Recently, boron-doped diamond (BDD) films have attracted much attention as electrode materials for electrochemical trace amount sensors and in dealing with wastewater. This is due to the excellent electrochemical properties BDD films possess, such as wide working potential window, low and stable voltammetric background current, and high stability against corrosion [1-3]. Therefore, BDD electrodes have been widely accepted as great contenders for electrochemical oxidation processes.

Research has shown that a major factor in BDD electrode properties is the boron concentration. In the research of Ndao et al., the influence of boron amount in diamond films was explored. It was concluded that only heavily boron-doped diamond films were efficient for inorganic and organic matter reduction [4]. Further research was conducted by Levy-Clement et al., in which the behavior of some metallic conductive diamond films grown by different groups was studied, especially the influence of the deposition methods and boron doping on the reduction process in solutions [5]. All tested electrodes with boron dosage of about $3 \times 10^{20} \mathrm{~cm}^{-3}$ showed an obvious reduction of matter.

In former research, a number of boron-doped diamond films were prepared by using a hot cathode direct current plasma chemical vapor deposition system with varied components of $\mathrm{CH}_{4} / \mathrm{H}_{2} / \mathrm{B}\left(\mathrm{OCH}_{3}\right)_{3}$ gas mixture [6]. The surface morphology, structure, bonding nature, and $\mathrm{B}$ concentration in the films were characterized by SEM and Raman analysis. It was found that a great deal of boron atom doping in the films could be achieved easily due to

\footnotetext{
* Corresponding author. Tel.: +86089865882863;

fax: +86089865882863. E-mail address: mdjphy@163.com (H.Y. Peng)
}

the higher plasma temperature and the more effective decomposition of the feeding gas in Hot Cathode Direct Current Plasma Chemical Vapour Deposition (HCDCPCVD) [7]. In this work, the electrochemical properties of BDD electrodes were characterized by electrochemical measurement. In order to explain the electrochemical performances of BDD electrodes, the concepts of interfacial energetics of semiconductor-electrolyte interfaces and the densities of mid-gap electronic states resulting from boron-doping were quoted.

\section{EXPERIMENTAL DETAILS}

BDD films were deposited using an HCDC-PCVD system. The BDD films deposition details have been described elsewhere [7]. Briefly, The DC glow discharge was held between a tantalum cathode with diameter of $70 \mathrm{~mm}$ and a copper anode that had been cooled with chilled water. The p-type crystalline Si (111) wafers were used as substrates. The reactant gas was a compound of high pure $\mathrm{CH}_{4}$ and $\mathrm{H}_{2}$ adjusted by mass flow controllers, and $\mathrm{B}\left(\mathrm{OCH}_{3}\right)_{3}$ was used as dopant source. This source was introduced into the chamber with an additional gas line of bubbling hydrogen. During the deposition the substrate temperature and the chamber pressure were kept at $800{ }^{\circ} \mathrm{C}$ and $13 \mathrm{kPa}$, respectively. The growth time for each sample was 7.5 hour. The parameters of the preparation are detailed in Table 1.

The morphology studies of BDD films were carried out by scanning electron microscopy (SEM, S-4800, Hitachi, Japan). X-ray diffraction patterns of BDD films were recorded on a D/max-2200/PC XRD instrument (Rigaku Co. Ltd., Tokyo, Japan). Raman measurements were characterized over a wave number range of $200 \sim 2000 \mathrm{~cm}^{-1}$ on the Raman spectrometer (inVia 
Raman, Renishaw Corporation, UK), equipped with an $\mathrm{Ar}$ ion laser of $514.5 \mathrm{~nm}$ wavelength.

Table 1. Deposition parameters of BDD films

\begin{tabular}{|c|c|c|c|}
\hline Sample & $\mathrm{CH}_{4}, \mathrm{sccm}$ & $\mathrm{H}_{2}, \mathrm{sccm}$ & $\mathrm{B}\left(\mathrm{OCH}_{3}\right)_{3}+\mathrm{H}_{2}, \mathrm{sccm}$ \\
\hline $\mathrm{a}$ & 4 & 200 & 0 \\
\hline $\mathrm{b}$ & 4 & 200 & 1 \\
\hline $\mathrm{c}$ & 4 & 200 & 2 \\
\hline $\mathrm{d}$ & 4 & 200 & 5 \\
\hline $\mathrm{e}$ & 4 & 200 & 10 \\
\hline $\mathrm{f}$ & 4 & 200 & 20 \\
\hline
\end{tabular}

The electrochemical properties and interfacial behavior of the BDD films were examined by cyclic voltammetry $(\mathrm{CV})$ in $0.1 \mathrm{M} \mathrm{Na} \mathrm{SO}_{4}$ blank solution and $0.2 \mathrm{mM} \quad \mathrm{K}_{4} \mathrm{Fe}(\mathrm{CN})_{6}$ and $\mathrm{K}_{3} \mathrm{Fe}(\mathrm{CN})_{6}$ mixed solution respectively, using an EG\&G Princeton Applied Research Model 263 in a conventional three electrodes configuration. All measurements were carried out in a single unit Teflon cell. For the sake of exposure of the diamond surface to the electrolyte solution, each BDD film that served as a working electrode was fastened to the bottom of the cell and given a hole with a radius about 0.7 $\mathrm{cm}$. A Pt wire and a commercially saturated $\mathrm{Ag} / \mathrm{AgCl}$ electrode were used as the counter electrode and the reference electrode respectively.

\section{RESULTS AND DISCUSSION}

The SEM images of the BDD films showed highly faceted surfaces with uniform texture, which can be seen in Fig. 1. a

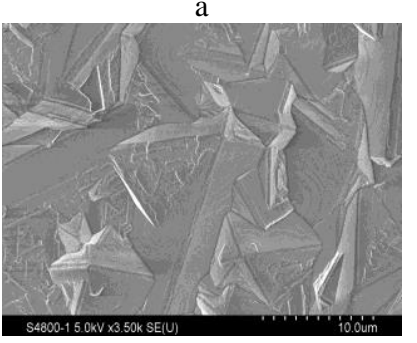

c

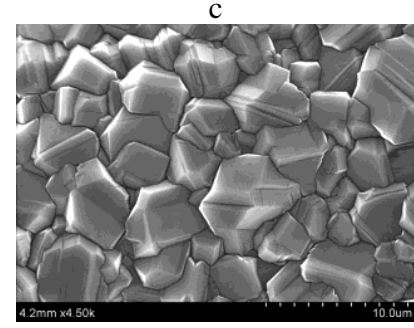

e

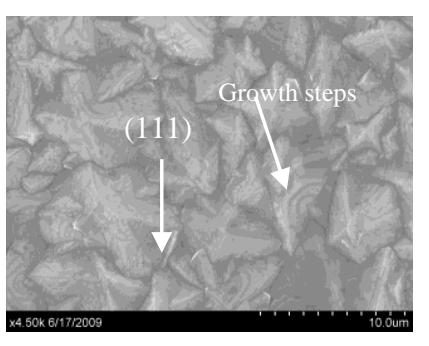

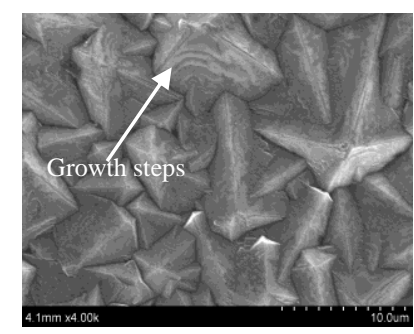

b

d

f
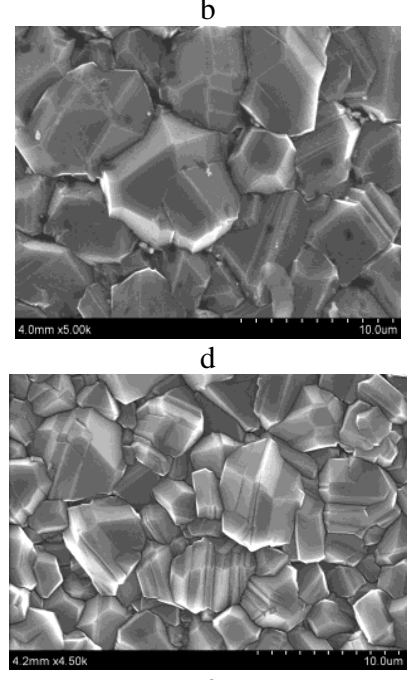

Fig. 1. SEM images of BDD films deposited at different B flowrate: $a-0 \mathrm{sccm}, \mathrm{b}-1 \mathrm{sccm}, \mathrm{c}-2 \mathrm{sccm}, \mathrm{d}-5 \mathrm{sccm}, \mathrm{e}-$ $10 \mathrm{sccm}, \mathrm{f}-20 \mathrm{sccm}$

The film had none and few B incorporation, as well as clear growth steps on the crystal faces [6], as indicated by white arrow in Fig. $1 \mathrm{a}$ and $\mathrm{b}$.

When the B content in the gas phase was increased, the (110) diamond texture increased and the growth steps on the crystal faces gradually diminished and finally disappeared. This would support the idea that B atoms introduced into BDD films benefit (110) direction growth. All of the BDD films were without obvious fissures, assuring the requisite protection of the substrates. Because of this, they are suitable for electrochemical application.

XRD spectrum of the typical BDD film (a) and (e) are shown in Fig. 2. The major lines identified were diamond (111), (220), (311), (400) and (331). The diffraction peaks of diamond were sharp lines with no broadening, indicating fine crystalline diamond. It could be seen clearly that diamond (111) peak was the highest among the other peaks. The peak relative strength of (220) to (111) was higher for sample (e) than (a), suggesting that B content in the films was favored for (110) orientation, the result was in consistent with that observed in SEM images in Fig. 1.

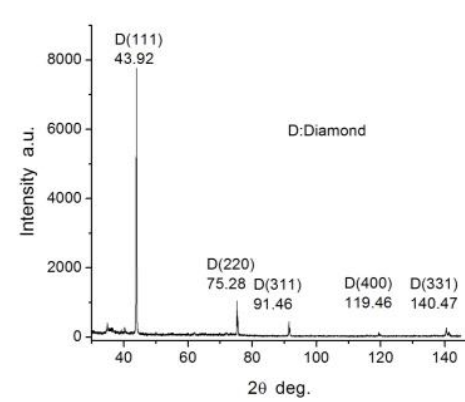

a

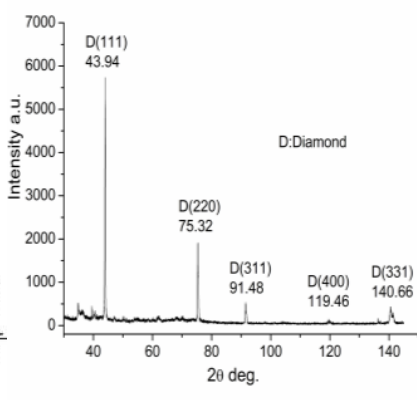

Fig. 2. XRD spectra of BDD films deposited at different B flow rate: $\mathrm{a}-0 \mathrm{sccm}, \mathrm{e}-10 \mathrm{sccm}$

The Raman spectra examples of the film (e) and (a) grown with $10 \mathrm{sccm} \mathrm{B}\left(\mathrm{OCH}_{3}\right)_{3}$ flow rates and without $\mathrm{B}\left(\mathrm{OCH}_{3}\right)_{3}$ in the feeding gas are shown in Fig. 3. More details analysis of all samples Raman characteristics were shown elsewhere [6]. Both Raman spectra revealed pointed peak at approximately $1332 \mathrm{~cm}^{-1}$, corresponding to the first-order Raman curve of diamond. There was a weak $\mathrm{G}$ band at $1585 \mathrm{~cm}^{-1}$ in the Raman spectrum of sample (a), which was assigned to graphite impurities located at the grain boundaries. However, the peak disappeared with the addition of boron in the films, implying that the incorporation of boron into the lattice structure of diamond may improve the quality of films. There were two broad peaks appeared at $\sim 500 \mathrm{~cm}^{-1}$ and $\sim 1210 \mathrm{~cm}^{-1}$ in the spectrum of film (e), which were reported as indicators of polycrystalline boron-doped films [8].

The following relationship between the boron concentration and the wavenumber of the Lorentzian component of the $500 \mathrm{~cm}^{-1}$ peak [9] was used to estimate the $\mathrm{B}$ doping concentration:

$[B] / \mathrm{cm}^{-3}=8.44 \times 10^{30} \exp (-0.048 \omega)$

where $\omega$ is the wavenumber position of the peak in $\mathrm{cm}^{-1}$.

The $\mathrm{B}$ contents were valued in this way as $1.75 \times 10^{19} \mathrm{~cm}^{-3}, \quad 1.63 \times 10^{20} \mathrm{~cm}^{-3}, \quad 6.68 \times 10^{20} \mathrm{~cm}^{-3}$, $2.40 \times 10^{21} \mathrm{~cm}^{-3}$, and $1.47 \times 10^{21} \mathrm{~cm}^{-3}$, for the films grown with B gas flux of $1 \mathrm{sccm}, 2 \mathrm{sccm}, 5 \mathrm{sccm}, 10 \mathrm{sccm}$, and 
$20 \mathrm{sccm}$, respectively. A clear increase in the B content was observed when the B flux in the feeding gas initial raised. However, when the flux was increased to $20 \mathrm{sccm}$, the $\mathrm{B}$ content decreased. This is possibly due to the decrease of precursor groups energy with the dropping of the plasma temperature in the active region when the $\mathrm{B}\left(\mathrm{OCH}_{3}\right)_{3}$ flow rate was increased abruptly.

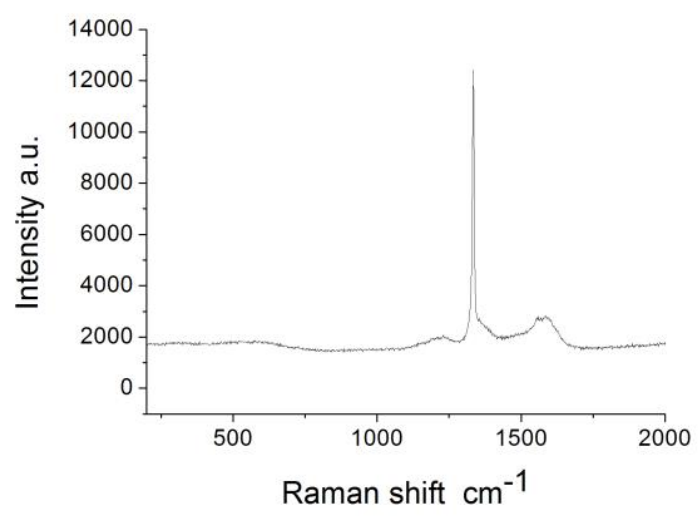

a

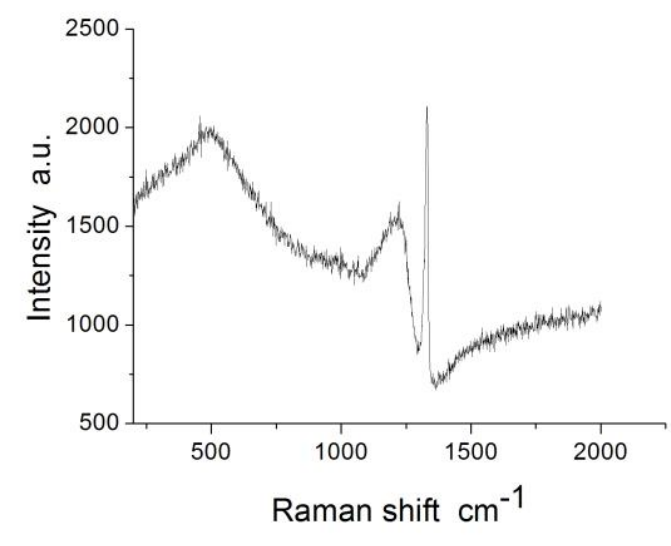

e

Fig. 3. Raman spectra of BDD films deposited at different B flow rate: $\mathrm{a}-0 \mathrm{sccm}, \mathrm{e}-10 \mathrm{sccm}$

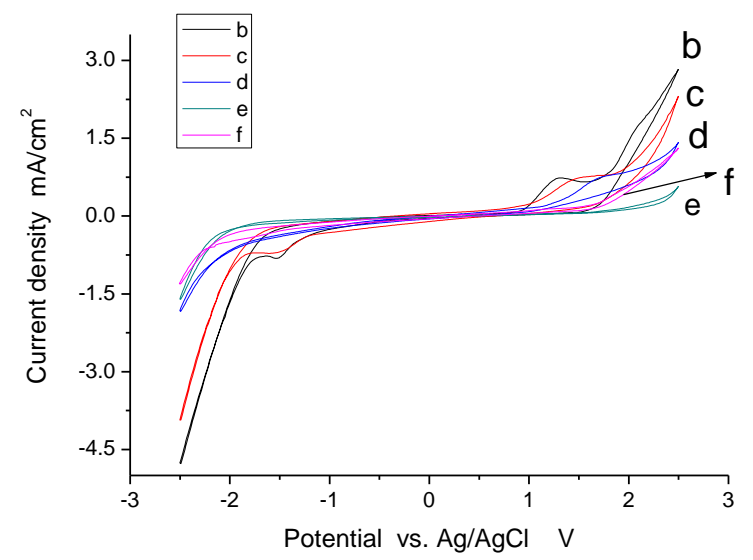

Fig. 4. The cyclic voltammograms curve of BDD electrodes in $0.1 \mathrm{M} \mathrm{Na}_{2} \mathrm{SO}_{4}$ solution, BDD electrodes with different doping level: $\mathrm{b}-1 \mathrm{sccm} ; \mathrm{c}-2 \mathrm{sccm} ; \mathrm{d}-5 \mathrm{sccm}$; e-10 sccm; f-20 sccm

The electrochemical properties of BDD films were measured by a $\mathrm{CV}$ scan in $0.1 \mathrm{M} \mathrm{Na} \mathrm{SO}_{4}$ aqueous solution to inspect the oxygen/hydrogen evolution behavior. In Fig. 4 cyclic voltammograms of BDD films with varied B concentration are shown, which were obtained in the potential range of -2.5 to $+2.5 \mathrm{~V}$ vs. $\mathrm{Ag} / \mathrm{AgCl}$. The background currents of all of the BDD electrodes were very low, suggesting superior electrochemical properties. The threshold potentials for oxygen evolution increased from $1 \mathrm{~V}$ to $2.5 \mathrm{~V}$. Meanwhile, the electrochemical potential windows of BDD electrodes enlarged from $2.2 \mathrm{~V}$ to $4.5 \mathrm{~V}$ when the $\mathrm{B}$ gas flow rate was increased from $1 \mathrm{sccm}$ to $10 \mathrm{sccm}$. Then, both decreased for BDD film deposited at $\mathrm{B}$ flow rate of $20 \mathrm{sccm}$, the potential of oxygen evolution decreased to $1.9 \mathrm{~V}$ and the potential window decreased to $3.4 \mathrm{~V}$. The highest $\mathrm{B}$ content in the film was deposited with $10 \mathrm{sccm} \mathrm{B}$ flow rate. From these measurements, we can see that an increase in the B content of the diamond film, resulted in improved electro-chemical properties of the BDD electrode.

Owing to lack of charge carrier, a cyclic voltammetric (CV) curve was not able to be successfully obtained for sample (a). For sample (b), (c) and (d), i.e. BDD films with lower B contents $\left(10^{19} \sim 10^{20} \mathrm{~cm}^{-3}\right)$, the cyclic voltammetric (CV) curves were shown to have shoulder-shaped anodic peaks on the forward sweep at $1.27 \mathrm{~V}(\mathrm{~b}), 1.45 \mathrm{~V}$ (c) and $1.71 \mathrm{~V}(\mathrm{~d})$, respectively, and cathodic peaks on the reverse sweep at $-1.4 \mathrm{~V}$ (b), $-1.5 \mathrm{~V}(\mathrm{c})$ and $-1.7 \mathrm{~V}$ (d) (very weak should peak), respectively. The anodic peak was ascribed to the oxidation of nondiamond carbon impurities at the surface, which presumably formed varieties of carbon oxygen groups [10]. The cathodic peak was assigned to the dissolved oxygen functionalities generated at the surface on the forward scan. When the B concentration in the films was increased $\left(\sim 10^{21} \mathrm{~cm}^{-3}\right.$, for sample (e), (f)), the anodic and cathodic peaks associated with the redox reactions of the nondiamond carbon were absent. This is an indication of the high quality of the films that exhibited no nondiamond carbon impurities, which is consistent with the results of the SEM and Raman spectra.

It should be noted that when the $\mathrm{B}\left(\mathrm{OCH}_{3}\right)_{3}$ flow rate was $10 \mathrm{sccm}$, which resulted in the BDD film with the highest $\mathrm{B}$ content, the electrode had the widest potential window, lowest background current, and highest oxygen evolution potential, i.e. the best electrochemical performances.

The interfacial process of sample (e) was investigated with $\mathrm{Fe}(\mathrm{CN}) 6^{-3 /-4}$ couple as the redox probe. Fig. 5 displays the $\mathrm{CV}$ curves of the BDD electrode obtained in an $0.2 \mathrm{mM} \mathrm{K}_{4} \mathrm{Fe}(\mathrm{CN})_{6}$ and $\mathrm{K}_{3} \mathrm{Fe}(\mathrm{CN})_{6}$ mixed solution at $50 \mathrm{mV} / \mathrm{s}$ scan rate for 10 circles. The cyclic voltammograms were asymmetric curves, showing the anodic current peak of $54.8 \mu \mathrm{A} / \mathrm{cm}^{2}$ at $0.288 \mathrm{~V}$, the cathodic current peak of $-69.7 \mu \mathrm{A} / \mathrm{cm}^{2}$ at $0.102 \mathrm{~V}$, with the potential difference between cathodic and anodic current peaks of the redox couple $\left(\Delta E_{\mathrm{p}}\right)$ of $186 \mathrm{mV}$. The reversibility level of a reaction could be deduced quantitatively from the cyclic voltammograms curves. On the basis of the electrode kinetics theory [10], for a reversible one-electron process, $\Delta E_{\mathrm{p}}=59 \mathrm{mV}$, despite the rate of the potential sweep and the reagent concentration at room temperature, with the cyclic voltammograms were well-defined symmetric curves, i.e., the cathodic and the 
anodic current peaks of the redox couple were equal $\left(i_{\mathrm{pa}} / i_{\mathrm{pc}}=1\right)$.

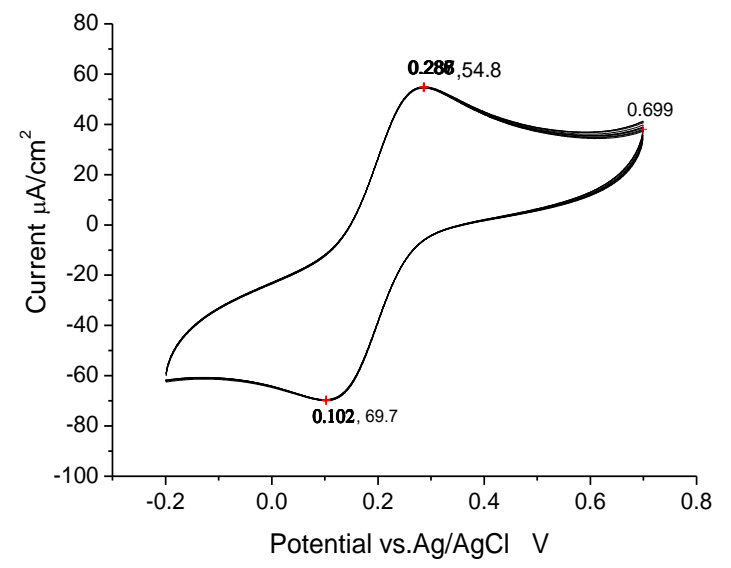

Fig. 5. The cyclic voltammograms curves of BDD electrode in $\mathrm{K}_{3}\left[\mathrm{Fe}(\mathrm{CN})_{6}\right]$ and $\mathrm{K}_{4}\left[\mathrm{Fe}(\mathrm{CN})_{6}\right]$ solution, the anodic current peak of $54.8 \mu \mathrm{A} / \mathrm{cm}^{2}$ at $0.288 \mathrm{~V}$, the cathodic current peak of $69.7 \mu \mathrm{A} / \mathrm{cm}^{2}$ at $0.102 \mathrm{~V}$

The reversibility of the electrode reaction decreased as $\Delta E_{\mathrm{p}}$ increased. The diamond electrode studied in this work showed $\Delta E_{\mathrm{p}}=186 \mathrm{mV}$, in excess of $59 \mathrm{mV}$, with the anodic peak currents were lower than the cathodic peak currents, (i.e., $i_{\mathrm{pa}} / i_{\mathrm{pc}}<1$ ), meaning that the reaction of $\mathrm{Fe}(\mathrm{CN}) 6^{-3 / 4}$ redox couple could be regarded as semireversible[11, 12]. Further and more thoroughly research about the electrochemical properties of the BDD films with varied $\mathrm{B}$ contents and different microstructure deposited by hot cathode direct current plasma CVD should be done next in order to reveal the interfacial process mechanism.

It has been pointed out that the electrochemical properties of BDD film can be influenced by interfacial energetics of the BDD-electrolyte interface, which are governed by the spatial dependence of the potential drop at the interface and the relative locations of the energy levels in the BDD bulk, surface states, and solution categories [13]. According to the Gerischer model [14], which is a well-accepted theory that is used to interpret electron transfers of semiconductor electrodes, electron transfer at a perfect semiconductor material is consistent with the density of occupied and unoccupied electronic states at the apparent potential (i.e.,cyclic voltammetric $E_{\mathrm{p}} / 2$ value) of the redox analyte. The energy values of the charge carriers and their absolute density at a given potential name the states density of an electrode. For an ideal wide band gap material as diamond, charge carriers flow is controlled by the closest band to the energy of the apparent potential of the redox analyte. The activation energy of boron-doped diamond films decreased as doping atoms increased due to a high density of impurity electronic states, which resulted from boron-doping electrical conduction that takes place through hopping. Metallic conduction came into being for BDD films at very high $\mathrm{B}$ concentrations resulting from the impurity band merging with the valence band. The activation energy of an isolated boron acceptor was about $0.37 \mathrm{eV}$, while for highly doped electrodes, the activation energies dropped as low as $0.002 \mathrm{eV}$ due to the formation of impurity band [15]. For this reason, the boron-doping concentration and uniformity were the principal factors governing the electrode kinetics. However, the relatively high $\Delta E_{\mathrm{p}}$ value found in this research indicates that there was an insufficient density of states at the potentials for relatively rapid electron transfer to occur. Further research is being conducted in order that the effect of B dopant- and other factors such as surface states, grain boundaries, and defects - on electrochemical reaction can be understood.

In addition, the fact that the curves were virtually unchanged for 10 swept circles indicated that the BDD film remained stable with cycling.

\section{CONCLUSIONS}

Several boron-doped diamond (BDD) films were deposited using hot cathode direct current plasma chemical vapor deposition with $\mathrm{CH}_{4} / \mathrm{H}_{2} / \mathrm{B}\left(\mathrm{OCH}_{3}\right)_{3}$, with a gas mixture flux varied from $4 / 200 / 1 \mathrm{sccm}$ to $4 / 200 / 20 \mathrm{sccm}$. Cyclic voltammograms of the BDD electrodes indicated that boron doping level was the dominant factor that determined the electrochemical characteristics of the electrodes.

For BDD films with lower B contents $\left(\sim 10^{20} \mathrm{~cm}^{-3}\right)$, the cyclic voltammetric curves showed shoulder-shaped anodic peaks and cathodic peaks. The anodic peaks were attributed to the oxidation of nondiamond carbon from the superficies, while the cathodic peaks were attributed to the reduction of them. When the $\mathrm{B}$ impurity concentration reached $\sim 10^{21} \mathrm{~cm}^{-3}$, the current peaks assigned to the redox reactions of the nondiamond carbon impurities were absent. This indicated the high quality of the films. The cyclic voltammograms of a BDD electrode in $0.2 \mathrm{mM}$ $\mathrm{K}_{4} \mathrm{Fe}(\mathrm{CN})_{6}$ and $\mathrm{K}_{3} \mathrm{Fe}(\mathrm{CN})_{6}$ mixed solution at $50 \mathrm{mV} / \mathrm{s}$ scan rate for 10 circles were well-defined symmetric curves. The $\Delta E_{\mathrm{p}}$ was $186 \mathrm{mV}$, and the anodic peak currents were less than the cathodic peak currents, i.e. $i_{\mathrm{pa}} / i_{\mathrm{pc}}<1$, indicating that the process of $\mathrm{Fe}(\mathrm{CN}) 6^{-3 /-4}$ redox couple could potentially be semi-reversible.

\section{Acknowledgement}

This work was supported by the National Nature Science Foundation of China (Project 51262007).

\section{REFERENCES}

1. Takeshi, W., Tomoko, K.S., Yoshitaka, T., Yousoo, K., Maki. K., Yasuaki, E. Giant Electric Double-Layer Capacitance of Heavily Boron-Doped Diamond Electrode Diamond and Related Materials 19 2010: pp.772-777.

2. Matsushima, J.T., Silva, W.M., $\quad$ Azevedo, A.F., Baldan, M.R., Ferreira, N.G. The Influence of Boron Content on Electroanalytical Detection of Nitrate Using BDD Electrodes Applied Surface Science 256 2009: pp. $757-762$. http://dx.doi.org/10.1016/j.apsusc.2009.08.055

3. Leide Lili G., S., Trava-Airoldi, V.J., Corat, E.J., Added, N., Sumodjo, P.T.A. Detection of N and B in Doped Diamond Films by ERDA Method and Related Electrochemical Characteristics Diamond and Related Materials 16 2007: pp.174-180.

4. Ndao, A.N., Zenia, F., Deneuville, A., Bernard, M., Le'vy-Cle'ment, C. Effect of Boron Concentration on the Electrochemical Reduction of Nitrates on Polycrystalline Diamond Electrodes Diamond and Related Materials 9 2000: pp. $1175-1180$. 
5. Levy-Clement, C., Ndao, N.A., Katty, A., Bernard, M., Deneuville, A., Comninellis, C., Fujishima, A. Boron Doped Diamond Electrodes for Nitrate Elimination in Concentrated Wastewater Diamond and Related Materials 12 2003: pp. 606-612.

6. Pan, M.M., Peng, H.Y., Zhao, W.B., Jiang, H.W, Structure and Raman Property of Boron-Doped Diamond Films Prepared by Hot Cathode Direct Current Plasma Chemical Vapor Deposition The 4th Global Conference on Materials Science and Engineering, CMSE 2015 (submitted).

7. Feng, Y.J., Lv, J.W., Liu, J.F., Gao, N., Peng, H.Y., Chen, Y.Q. Influence of Boron Concentration on Growth Characteristic and Electro-Catalytic Performance of BoronDoped Diamond Electrodes Prepared by Direct Current Plasma Chemical Vapor Deposition Applied Surface Science 257 2011: pp. 3433-3439.

8. Goss, J.-P., Briddon, P.-R. Theory of Boron Aggregates in Diamond: First-Principles Calculations Physics Review B 73 2006: pp. 085204-085208. http://dx.doi.org/10.1103/PhysRevB.73.085204

9. Bernard, M., Deneuville, A., Muret, P. Non-Destructive Determination of the Boron Concentration of Heavily Doped Metallic Diamond Thin Films from Raman Spectroscopy Diamond and Related Materials 13 2004: pp. $282-286$.

10. Torz-Piotrowska, R.,

Fabisiak, K., $\quad$ Paprocki, K., Szybowicz, M., Staryga, E., Banaszak, A. Electrochemical
Properties of Undoped CVD Diamond Films Journal of Physics and Chemistry of Solids 72 2011: pp. 1225-1229. http://dx.doi.org/10.1016/j.jpcs.2011.07.009

11. Shalini, J., Lin, Y.C., Chang, T.H., Kamatchi, J.S., Chen, H.C., Lin, I.N., Lee, C.Y., Tai, N.H. UltraNanocrystalline Diamond Nanowires with Enhanced Electrochemical Properties Electrochemistry Acta 92 2013: pp. 9-19.

12. Pan, J.P, Hu, X. J., Lu, L.P., Yin, C. Influence of Annealing on the Microstructure and Electrochemical Properties of B-Doped Nanocrystalline Diamond Films ACTA Physica Sinica 59 (10) 2010: pp. 7410-7416 (in chinese).

13. Van de Lagemaat, J., Vanmaekelbergh, D., Kelly, J.J. Electrochemistry of Homoepitaxial CVD Diamond: Energetics and Electrode Kinetics in Aqueous Electrolytes Journal of Electroanalytical Chemistry 475 1999: pp. 139-151.

14. Koval, C.A., Howard, J.N. Electron Transfer at Semiconductor Electrode-Liquid Electrlolyte Interfaces Chemical Reviews 92 1992: pp. 411-434. http://dx.doi.org/10.1021/cr00011a004

15. Granger, M.C., Witek, M., Xu, J.S., Wang, J., Hupert, M., Hanks, A., Koppang, M.D., Butler, J.E., Lucazeau, G., Mermoux, M., Strojek, J.W., Swain, G.M. Standard Electrochemical Behavior of High-Quality,BoronDoped Polycrystalline Diamond Thin-Film Electrodes Analytical Chemistry 72 (16) 2000: pp.3793-3804. 